\title{
Dynamic Range Enhancement for Flameless Zeeman Atomic Absorption Spectroscopy
}

\author{
Masao S. Hashimoto*, Hideo Yamada**, Kohnosuke OHIShI** and Kazuo YasudA*** \\ *Hitachi Instrument Engineering Co. Ltd., Ichige, Katsuta 312 \\ **Naka Works, Hitachi Ltd., Ichige, Katsuta 312 \\ ***Instrumental Division, Hitachi Ltd., Marunouchi 1, Tokyo 100
}

\begin{abstract}
A method of extending the dynamic range in flameless ZAAS (Zeeman atomic absorption spectroscopy) was proposed. The calibration curve in this method was made as follows: Slice the absorbance-time profile at a height $A w_{1}$ which is higher than (1/20) $A_{0}$ and lower than (1/2) $A_{0}$, where $A_{0}$ is the peak height and $W_{t}$ is the width resulted from this slicing procedure. The slicing was done so as to give a constant $W_{1}$ for all the aliquot of the solutions. It was shown that the dynamic range can be extended more than 10 times compared to the usual peak height method.
\end{abstract}

Keywords Flameless Zeeman AAS, dynamic range, full width at half maximum, calibration curve

The dynamic range of the atomic absorption spectroscopy (AAS) is known to be limited to one or two orders of range. This has been one of the reason preventing the development of the instrument for simultaneous multielement measurement. ${ }^{1}$ One of the way to overcome this is to reduce the sensitivity by the rotation of burner head or by the use of less sensitive lines. It is also useful to make AAS measurement on sides of the absorption profile by using the continuum light source. ${ }^{2}$ The profile in flameless AAS is determined by the mechanisms of atom formation and dissipation in the electrothermal furnace. Many authors have investigated about mechanisms and found that the theoretical prediction of the profile corresponds well to the experimental profile..$^{3-14}$ None of them, however, has suggest the possibility of the width of the profile being used to make a calibration curve for the analysis. Sturgeon et al. ${ }^{3}$ discussed the peak-height vs. peakarea method of making a calibration curve and found that the peak-area method could extend the dynamic range a little.

In the present paper, we propose another way to extend the dynamic range in flameless Zeeman atomic absorption spectroscopy (ZAAS) by measuring the absorbance at constant width in absorbance-time profile. As a result, the dynamic range of the calibration curve was found to be extended to more than 10 times comparing to the method using the peak-height of the absorbance-time profile.

\section{Experimental}

Hitachi model Z-7000 atomic absorption spectrometer equipped with Zeeman background correction and fitted with a commercial graphite tube atomizer was used without any modification. Argon sweep gas was reduced to zero from $30 \mathrm{ml} / \mathrm{min}$ during atomization. The measurement conditions are indicated in

Table 1 Measurement conditions $\mathrm{s}^{\mathrm{a}}$

\begin{tabular}{ccccccc}
\hline & $\begin{array}{c}\text { Lamp current } \\
\mathrm{mA}\end{array}$ & Wavelength/ & \multicolumn{3}{c}{ Heating $\left({ }^{\circ} \mathrm{C} ; \mathrm{s}\right)^{\mathrm{b}}$} \\
\cline { 5 - 6 } & & $\mathrm{nm}$ & Dry & Ash & Atomize & Clean \\
\hline $\mathrm{Cu}$ & 7.5 & 324.8 & $60-120 ; 40$ & $950 ; 30$ & $2800 ; 20$ & $2800 ; 15$ \\
$\mathrm{Cd}$ & 7.5 & 228.8 & $60-90 ; 40$ & $300 ; 30$ & $2200 ; 20$ & $2200 ; 30$ \\
$\mathrm{~Pb}$ & 7.5 & 283.3 & $60-90 ; 40$ & $500 ; 30$ & $2500 ; 20$ & $2800 ; 30$ \\
$\mathrm{Cr}$ & 10 & 359.3 & $80-120 ; 40$ & $700 ; 30$ & $2900 ; 20$ & $3000 ; 30$ \\
\hline
\end{tabular}

a. $10 \mu \mathrm{l}$ sample sizes in all cases.

b. Ar sweep gas reduced to zero from $30 \mathrm{ml} / \mathrm{min}$ during atomization. 
Table 1. The sample solutions were prepared from 1000 ppm AAS standard solutions (Kanto Kagaku Co., Ltd.) by diluting with deionized water.

According to L'vov', the rate of change of number of atoms $N_{\mathrm{w}}$ in the furnace (atomizer) can be expressed by the equation

$$
\mathrm{d} N_{\mathrm{w}} / \mathrm{d} t=n_{1}(t)-n_{2}(t)
$$

where $n_{1}(t)$ is the amount of the enterring atoms and $n_{2}(t)$ is those of leaving atoms in unit time. De Galan et $a .^{5}$ indicated that $n_{1}(t)$ is determined by the temperature of the furnace $T_{\mathrm{w}}$, and by the frequency factor $B$, and the activation energy of the dominant analyte release process from the wall of the furnace $E_{\mathrm{w}}$ :

$$
\begin{aligned}
n_{1}(t)= & N_{\mathrm{w}} B \exp \left[-E_{\mathrm{w}} / R T_{\mathrm{w}}(t)\right] \\
= & N\left(t_{0}\right) B \exp \left[-E_{\mathrm{w}} / R T_{\mathrm{w}}\right] \\
& \times \exp \left[-\int_{0}^{t} B \exp -E_{\mathrm{w}} / R T_{\mathrm{w}}\left(t^{\prime}\right) \mathrm{d} t^{\prime}\right]
\end{aligned}
$$

$n_{2}(t)$ is determined by either convection (in flowthrough systems) or diffusion (in static):

$$
n_{2}(t)=N\left(t_{0}\right) \exp \left(-t / \tau_{\mathrm{R}}\right)
$$

where $\tau_{\mathrm{R}}$ is the time constant of the overall leaving process, which is composition of the expulsion of the analyte from the furnace due to the expansion of the vapor inside the furnace, the convective transport of the vapor from the furnace, and the diffusion process. From eqs. (1) to (3), eq. (1) can be rewritten by a form of the product of time-independent part $N\left(t_{0}\right)$, which corresponds to the initial concentration of the analyte and the time-dependent part $F(t)$ :

$$
\mathrm{d} N_{\mathrm{w}} / \mathrm{d} t=N\left(t_{0}\right) F(t)
$$

The integration of (4) was carried by Sturgeon et al. $^{3}$ but we do not need the precise form at present. Anyway, the concentration of the analyte plays only a role of the amplitude in the absorbance-time profile. The so-called peak-height method in making a calibration curve in flameless AAS is just based upon this fact. Therefore, we can discuss about the full width half maximum (FWHM), $W_{\mathrm{t}}\left[(1 / 2) A_{0}\right]$, like a profile of chromatography, of which analytical form can be approximated, for example, by a skewed Gaussian distribution. ${ }^{15}$ The FWHM is independent of concentration. The FWHM in flameless AAS is therefore expected to be a constant and to depend only upon the kind of analyte and the measurement conditions.

At first, we check whether this is satisfied or not. If this is satisfied, next step is to see how about the other line widths, that is, $W_{\mathrm{t}}\left[(1 / 3) A_{0}\right], W_{\mathrm{t}}\left[(1 / 4) A_{0}\right] \cdots$, etc. If these are also independent of the concentration, noth-
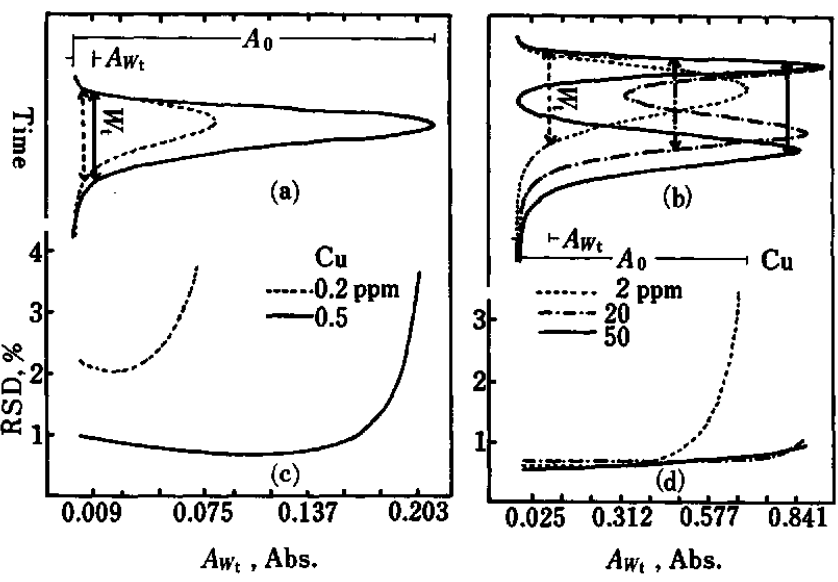

Fig. 1 Absorbance-time profiles (a), (b) for $\mathrm{Cu}$. The curves (c), (d) show the reproducibility for respective profiles.

Table 2 Observed $W_{t}$ and their dependency upon the concentration of $\mathrm{Cu}$

\begin{tabular}{lcccc}
\hline & \multicolumn{4}{c}{$W_{t}$ (in arbitrary unit) } \\
\cline { 2 - 5 } & $2 \mathrm{ppm}$ & $1 \mathrm{ppm}$ & $0.5 \mathrm{ppm}$ & $0.2 \mathrm{ppm}$ \\
\hline$(1 / 2) A_{0}$ & 1.6 & 1.6 & 1.6 & 1.6 \\
$(1 / 3) A_{0}$ & 2.0 & 2.0 & 2.1 & 2.1 \\
$(1 / 4) A_{0}$ & 2.3 & 2.2 & 2.4 & 2.4 \\
$(1 / 8) A_{0}$ & 2.8 & 2.8 & 3.0 & 3.0 \\
$(1 / 10) A_{0}$ & 3.5 & 3.5 & 3.3 & 3.4 \\
\hline
\end{tabular}

ing more is needed to know the peak heights $A_{0}$ for making a calibration curve. What is needed is only measuring the heights $A_{W}$ at a value of line width $W_{\mathrm{t}}$ (see arrows in Fig. 1(a), for example). This is quite useful to extend the dynamic range of the calibration curve in ZAAS where the so-called roll-over phenomenon is observed in higher concentration region ${ }^{16}$ and the peak top can not be found (see Fig. 1(b), for example).

\section{Results and Discussion}

Table 2 indicates the relation of various line widths including FWHM with concentration. From this it is concluded that not only FWHM but also other widths are also independent of the concentration within experimental errors.

Figures 1-4 indicate the absorbance-time profiles in the flameless Zeeman AAS for various concentration of analyte solutions. In these figures, the profiles in lower and higher region of concentration were marked as (a) and (b), respectively.

The calibration curves were obtained by measuring the heights $A_{w_{t}}$ at the widths $W_{t}=3.6(\mathrm{Cu}), 1.5(\mathrm{Cd}), 3.3$ $(\mathrm{Pb})$ and $5.4(\mathrm{Cr})$ in a scale of the recorder chart and 

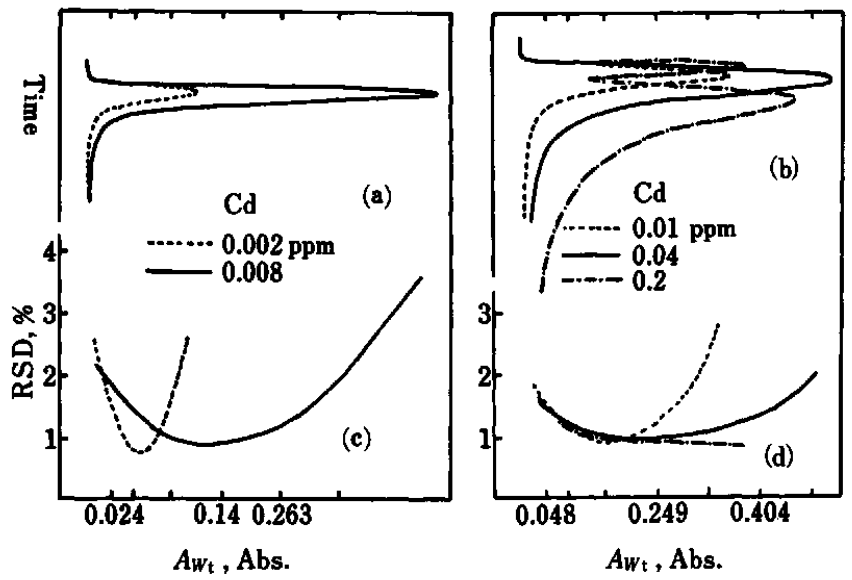

Fig. 2 Absorbance-time profiles (a), (b) for Cd. The curves (c), (d) show the reproducibility for respective profiles.
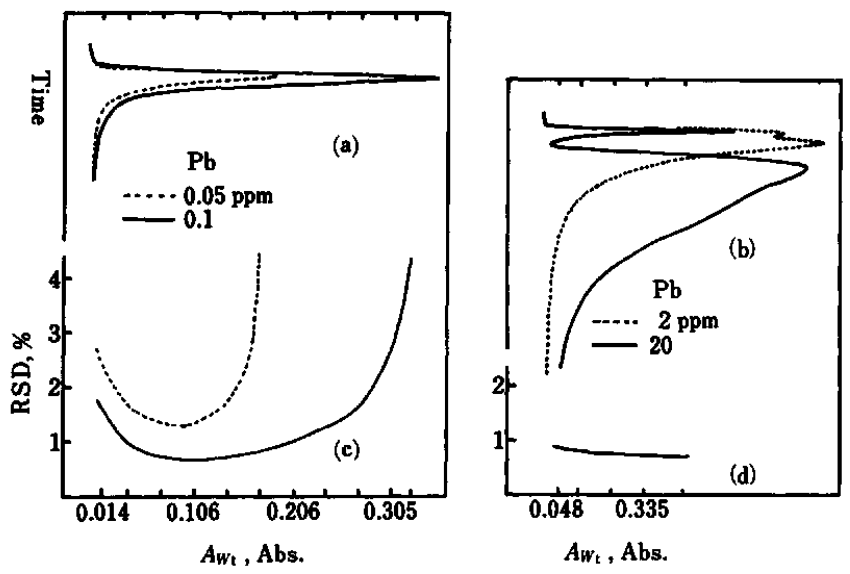

Fig. 3 Absorbance-time profiles (a), (b) for $\mathrm{Pb}$. The curves (c), (d) show the reproducibility for respective profiles.
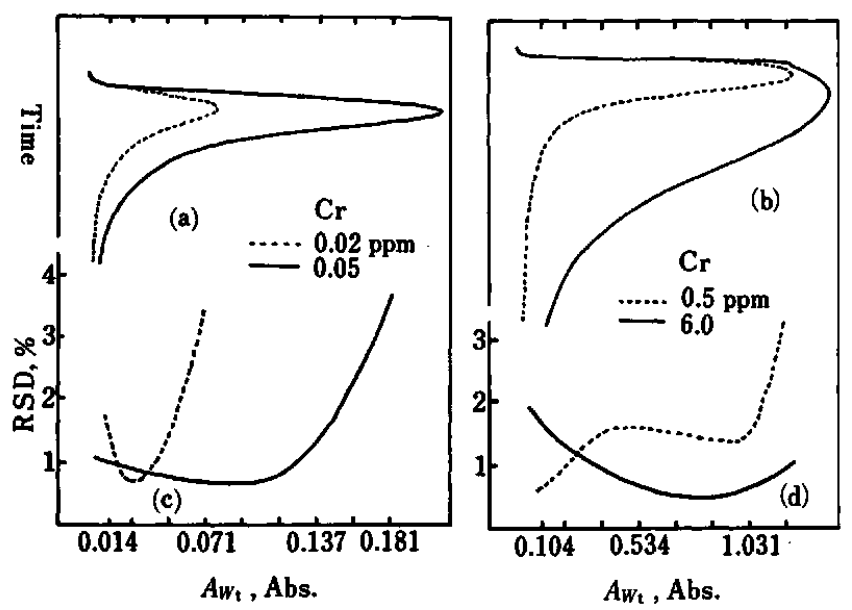

Fig. 4 Absorbance-time profiles (a), (b) for $\mathrm{Cr}$. The curves (c), (d) show the reproducibility for respective profiles.
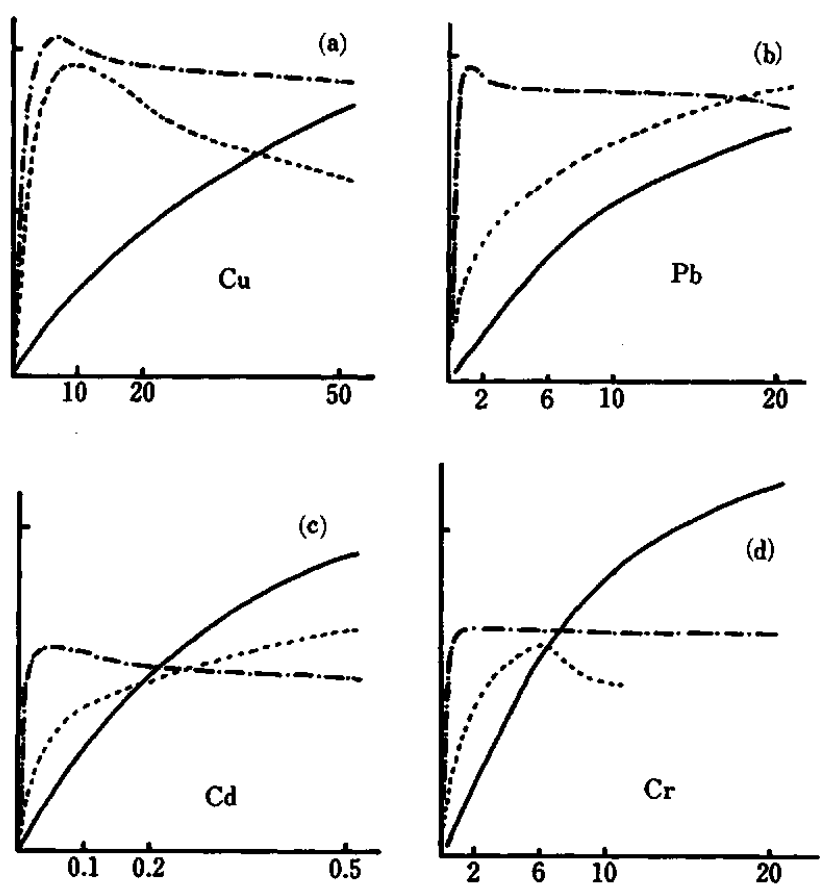

Fig. 5 Calibration curves by using height at a width (-),

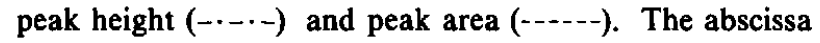
is showing the concentration of analyte (ppm).

Table 3 Multielement solution (in ppm)

\begin{tabular}{lllll}
\hline Al 10, & Cd 2, & Hg 1, & P 70, \\
As 5, & Cr 2.5, & $\mathrm{Mo} \mathrm{1,}$ & $\mathrm{Pb} 2$, \\
B 1.5, & $\mathrm{Cu} 2$, & $\mathrm{Na} \mathrm{20,}$ & $\mathrm{Sr} 0.1$, \\
$\mathrm{Ba} 0.5$, & $\mathrm{Fe} 1.5$, & $\mathrm{Ni} 5$, & $\mathrm{Zn} 2$ \\
\hline
\end{tabular}

are indicated in Fig. 5(a)-(d). In comparison with the curve obtained by using the peak heights $A_{0}$ or peak areas, the dynamic range is seen to extend 10 times more.

In order to check the precision of this method, the reproducibility of the height $A_{w_{1}}$ at a line width $W_{1}$ was checked by measuring the profiles 20 times repeatedly. The results are shown in Figs. 1-4. From this it can be seen that the relative standard deviation (R.S.D.) of the $A_{w t}$ is better $(0.48-1.0 \%)$ at the points near around $W_{\mathrm{t}}=$ FWHM. The R.S.D. value at the points near to the peak top is rather worse $(5 \%)$ even if there is not a roll-over phenomenon. On the contrary, the R.S.D. value at the points below $A_{\text {FWHM }}$ is not so worse $(0.5-1.5 \%)$ if $A$ is higher than (1/20) $A_{0}$.

At the beginning of the atomization, the amount of the leaving atoms is negligible in comparison with that of the enterring atoms in the furnace because the rate constant of the dissipation procedure is considered to be smaller than that of the formation. ${ }^{9}$ As the time passes, the amount of enterring atoms decreases and becomes same order as that of the leaving atoms near around the top of the profile. Each point of the 
profile is, therefore, fluctuating in these region. On the peak top of the profile the fluctuation is small because the procedure of atom formation is negligible there. This is the reason why the R.S.D. value at the points below $A_{\text {FWHM }}$ is rather better than those at the points near the peak top.

Thus, the precision of the present method is guaranteed if the measurement is done at a height $A$ w higher than (1/20) $A_{0}$ and below (1/2) $A_{0}$.

It is important to see the effect of the chemical intereference on the form of the absorbance-time profile. The addition of the acid $\left(3 \mathrm{M} \mathrm{HCl}, \mathrm{HNO}_{3}\right.$ and $\mathrm{H}_{2} \mathrm{SO}_{4}$ ) made a depression of the absorbance but did not cause any distortion of the profile. Furthermore, coexisting elements in a mixture of 16 elements (see Table 3) did not distort the profile of the analytes. More thorough study about the chemical interferences is being done and will be published elsewhere.

\section{References}

1. J. M. Harnly and J. S. Kane, Anal. Chem., 56, 48 (1984).

2. J. M. Harnly and T. C. O'Haver, Anal. Chem., 53, 1291 (1981).
3. R. E. Sturgeon, L. C. Chakrabarti, I. S. Maines and P. L. Berteis, Anal. Chem., 47, 1240 (1975).

4. G. Torsi and G. Tessari, Anal. Chem., 47, 839 (1975).

5. W. M. G. T. van den Broek and L. de Galan, Anal. Chem., 49, 2176 (1977).

6. S. Akman, Ö. Genc, A. R. Özdural and T. Balkis, Spectrochim. Acta, Part B, 35, 373 (1980).

7. S. Akman, Ö. Genc and T. Balkis, Spectrochim. Acta, Part B., 36, 1121 (1981).

8. B. Smets, Spectrochim. Acta, Part B., 35, 33 (1980).

9. B. V. L'vov, Spectrochim. Acta, Part B., 33, 153 (1978).

10. J. A. Holcombe, Spectrochim. Acta, Part B., 38, 609 (1983).

11. E. Lundberg and G. Johansson, Anal. Chem., 48, 1922 (1976).

12. C. Chung, Anal. Chem., 56, 2714 (1984).

13. R. E. Sturgeon, C. L. Chakrabarti and C. H. Langford, Anal. Chem., 48, 1792 (1976).

14. S. L. Paveri-Fontana, G. Tessari and G. Torsi, Anal. Chem., 46, 1032 (1974).

15. H. M. Gladney, B. F. Dowden and J. D. Swalen, Anal. Chem., 41, 883 (1969).

16. M. T. C. de Loos-Vollebregt and L. de Galan, Appl. Spectrosc., 34, 464 (1980); ibid., 38, 141 (1984).

(Received December 14, 1985) (Accepted February 3, 1986) 